\title{
The role of transvaginal ultrasound in the management of abnormal uterine bleeding
}

Published online: 3 March 2004

(C) Springer-Verlag Berlin / Heidelberg 2004

\begin{abstract}
Abnormal uterine bleeding is a common symptom. Modern management should be based on a "onestop" approach to which transvaginal ultrasound is ideally suited as a primary diagnostic tool. In premenopausal women focal pathology, such as fibroids and polyps, as well as extra uterine pathology, can be accurately diagnosed. In postmenopausal women endometrial cancer can be excluded. In the majority of women diagnostic hysteroscopy can thus be avoided, and patients with focal pathology detected with transvaginal ultrasound can be triaged for operative intervention. Outpatient endometrial biopsy should still be used to exclude endometrial pathology. This one-stop ultrasound-based clinical approach provides a rapid, accurate diagnosis, with the minimum of investigations and invasive procedures. In this way multiple outpatient visits and unnecessary inpatient admissions can be avoided.
\end{abstract}

Keywords Postmenopausal bleeding - Transvaginal ultrasound · Polyp · Fibroid · Adenomyosis

\section{Introduction}

Abnormal uterine bleeding (AUB) can occur at any stage of a woman's life. Although the cause is usually benign pathology, it can be a cause of anxiety for the patient and usually warrants investigation to exclude any sinister underlying pathology. Patients who present with AUB make up a significant proportion of the caseload in the gynaecology clinic. Outpatient assessment and investigation has changed the management of many common gynaecological conditions. This change has been driven by the demands of both patients and clinicians to provide rapid, accurate diagnosis, with a minimum of investiga-

E. Okaro $(\bowtie) \cdot$ G. Condous · T. Bourne

Gynaecological Ultrasound and Minimal Access Surgery Unit,

St. George's Hospital Medical School,

Cranmere Terrace, Tooting London, SW17 0RE, UK

e-mail: cokaro@aol.com tions, invasive procedures and in particular hospital visits, which are often expensive and time-consuming.

Transvaginal ultrasonography (TVS) plays an important role in the assessment of women with AUB. Transvaginal probes provide high-resolution images of the pelvic organs, providing reliable and reproducible information [1]. The fact that a full bladder is not required improves patient acceptability.

Patients with AUB are ideally suited to assessment by transvaginal ultrasonography at the time of presentation or assessment in the outpatient setting. A scan should be seen as a part of the overall clinical assessment of the patient and never examined in isolation. There are obvious advantages to the gynaecologist performing the scan as they can weigh up all the available information about the patient and place the scan findings in the correct context. An accurate scan can enable the clinician to avoid surgery in some cases and select the correct surgical approach in others. In women with AUB, TVS can be combined with outpatient endometrial sampling techniques as part of a "one-stop" approach to diagnosis and management [3]. The basic requirements for ultrasonography are a transvaginal probe $(5-7.5 \mathrm{MHz})$, a $3.5-\mathrm{MHz}$ transabdominal transducer and facilities for capturing images, either as a hard copy or digitally. The facility to perform Doppler studies or carry out three-dimensional ultrasonography is not essential. The transducer should be cleansed with a germicidal (e.g. $70 \%$ alcohol) cloth or spray effective in preventing cross infection.

This review aims to deal with the role of ultrasonography (in particular TVS) in the assessment of the patient presenting with AUB, in which gynaecological pathology is suspected. Transvaginal ultrasonography as an extension of the clinical examination may not diagnose the cause of all presenting complaints; however, the failure to demonstrate pathology can be highly reassuring and obviate the need for further investigation 


\section{Saline infusion sonography}

Saline infusion sonography (SIS) is a simple technique involving the instillation of sterile saline into the uterine cavity $[4,5,6]$. A bi-valve speculum is used to visualise the cervix, then a catheter is used to instil the saline through the cervical canal into the uterine cavity. We use a 5-F paediatric nasogastric feeding tube. A number of catheters with or without balloon catheters are commercially available. The balloon helps to reduce backflow of saline and maintain uterine distension; however, in our experience they are rarely needed. The balloon devices tend to more expensive, are not readily available and distension of the balloon at the internal cervical os can cause increased discomfort, and obscure the view in the lower aspect of the cavity. The SIS facilitates the generation of clear images of the endometrial cavity and this obviates the need for hysteroscopy in the majority of women.

Indications for SIS are as follows:

1. Thickened or irregular endometrium

2. Poor views of the endometrium, e.g. due to axial position of uterus or a large fibroid distorting the cavity.

3. Preoperative localisation, size and relation to cavity of submucous fibroids/endometrial polyps prior to hysteroscopic surgery.

Transvaginal ultrasonography is a well-tolerated procedure, even when SIS is performed the routine use of analgesia is not required in most cases [7, 8]. In a randomised trial Timmerman et al. [9] demonstrated that patients preferred TVS with SIS to outpatient hysteroscopy. The SIS should not be performed in the presence of overt pelvic infection. Although the risk of pelvic infection following SIS is very small, in our practice we give prophylactic antibiotics to all potentially fertile women. An important practical requirement is a database system for archiving ultrasound images and producing reports. This enables the operator to produce a report as soon as the scan has been completed and facilitates audit and clinical review.

The normal endometrial pattern

The uterus should be assessed in the two major scanning planes. The view in the sagittal plane should include the cervical canal, the body of the uterus, the fundus and the endometrial cavity. The coronal view is important as it allows assessment of the uterus in the transverse plane, which may be helpful in identifying focal pathology suspected in the sagittal view and in the diagnosis of congenital uterine abnormalities. The endometrial thickness should be measured as described by Granberg et al. [10]. This is the maximal measurement across the lumen of the endometrial cavity from one endometrial-myometrial interface to another (Fig. 1). This measurement

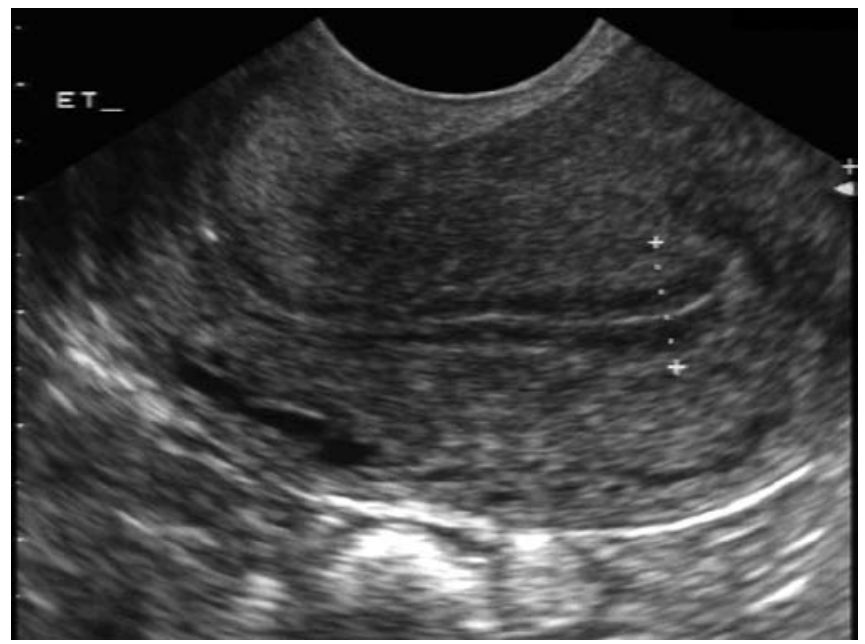

Fig. 1 Sagittal transvaginal image of a retoverted uterus with a periovulatory endometrial pattern. The dotted line indicates the endometrial thickness. A three-layer endometrium is noted: the endometrial lumen is demonstrated by the central echogenic line, the hypoechogenic layer representing the edematous endometrial functionalis and an outer echogenic area representing the endometrium basalis

excludes intracavity fluid but includes any tissue. It is usually obtained just below the fundus. Whereas there are extensive data on normal values for the postmenopausal endometrium $[11,12,13,14]$, there are scant normative data for the premenopausal endometrium. The studies that have looked at endometrial thickness in premenopausal women have involved relatively small numbers of patients $[15,16]$. In postmenopausal women endometrial thickness of $4 \mathrm{~mm}$ or less is associated with endometrial atrophy. In premenopausal women the endometrial thickness varies from 4 to $8 \mathrm{~mm}$ in the follicular phase and from 7 to $14 \mathrm{~mm}$ in the secretory phase. In general, however, the endometrium must be thought of as a dynamic structure that undergoes cyclical changes that are synchronous with the variations of the menstrual cycle. Persisting thick endometrium may be pathological and an "unmeasurable" endometrium should not be accepted as probably being normal. In practice, the stage of the cycle when a scan is performed may influence the likelihood of finding focal pathology. Secretory endometrium is often hyperechoeic, which may mask focal pathology, and when polypoid this may lead to the erroneous diagnosis of focal endometrial pathology. The ideal time to perform an ultrasound scan is either just after a period or in the middle of the cycle as focal pathology is easily differentiated in periovulatory endometrium. A scan should always be repeated at the appropriate stage of the cycle. If the findings are unclear, SIS should be performed to try to clarify the situation if there is any doubt. If it is still unclear, in symptomatic patients this is an indication for an endometrial biopsy and further assessment of the cavity by means of hysteroscopy. 


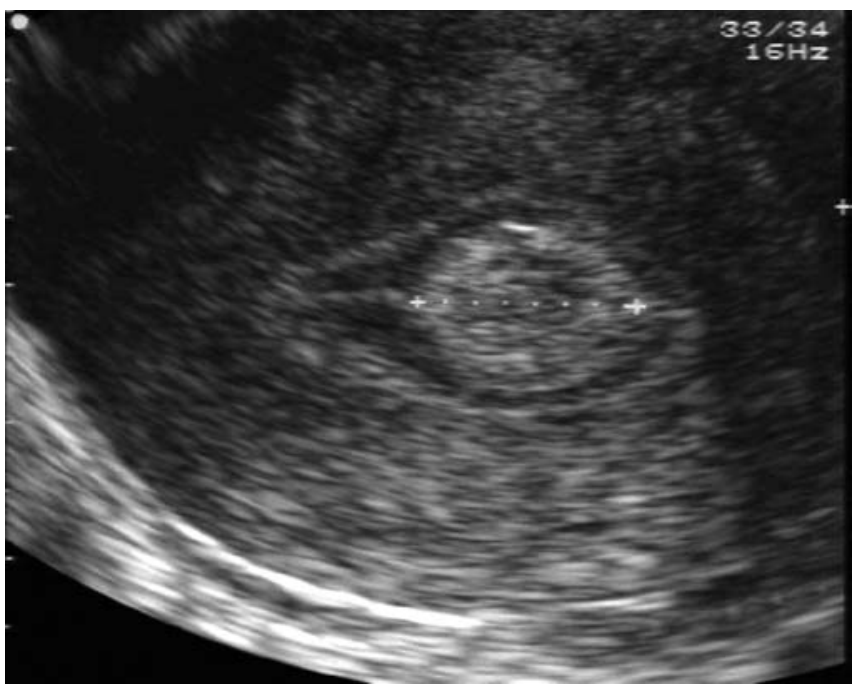

Fig. 2 A coronal view of a uterus depicting an endometrial polyp, in a triple-line periovulatory endometrium

The "one-stop" ultrasound-based clinic

All too often in the UK patients with AUB often endure multiple hospital visits for assessment, investigations and treatment. In-patient hysteroscopy under general anaesthesia no longer has a role in the first-line management of abnormal uterine bleeding. Increasingly, out patient-based management strategies are being established to avoid multiple visits and tests $[17,18]$. These "one-stop" clinics are generally based on flexible or rigid hysteroscopy, with directed or blind endometrial biopsies; however, the TVS/ SIS-based one stop clinic is a logical alternative strategy, as the primary diagnostic tool in combination with blind endometrial biopsy. The role of a scan in the context of AUB is to differentiate between focal and global endometrial pathology. Hysteroscopy is currently still the gold standard for uterine cavity evaluation $[19,20]$; however, TVS, with or without the addition of saline as a negative contrast agent, compares favourably [7, 8, 9, 21]. In one study ultrasound alone was poor in detecting focal pathology [22]; however, SIS improved the detection of focal lesions significantly. This suggests that SIS may deskill the procedure. We have found that in experienced hands SIS becomes less important as most focal pathology can be identified on TVS alone (Fig. 2). Furthermore, TVS allows the assessment of the adnexa for of extrauterine pathology, e.g. endometrioma.

\section{Postmenopausal bleeding}

The average age of the menopause in the UK is 51 years, and women still menstruating after the age of 55 years should be investigated. About 5\% of women attending gynaecological clinics present with postmenopausal bleeding (PMB). The majority of women with PMB will have a benign cause for their bleeding, the commonest being genital tract atrophy; however, $10 \%$ will have a primary or secondary malignancy. The commonest malignancy is endometrial cancer of which $80 \%$ present with PMB. The risk of endometrial cancer in women with PMB increases with age from about $1 \%$ at the age of 50 years to $25 \%$ at the age of 80 years. The TVS is the first-line investigation of choice in the assessment of PMB. There is good evidence in the literature to show that irrespective of hormone use, an endometrial thickness measurement of $4 \mathrm{~mm}$ or less is associated with endometrial atrophy $[10,12,13,23,24]$. Irrespective of hormone replacement therapy (HRT) use, using a $>4-\mathrm{mm}$ cutoff value to define an abnormal endometrium, $96 \%$ of women with endometrial cancer and $92 \%$ of women with endometrial disease (hyperplasia, polyps and fibroids) will have an abnormal result, with a false-positive rate of 39 and $19 \%$, respectively [25].

The high sensitivity of TVS makes it an effective noninvasive test for selecting women with vaginal bleeding who do not require an endometrial biopsy. Conversely, its relatively poor specificity means that an abnormal endometrial thickness measurement needs to be followed up by a second stage test in the form of an endometrial biopsy. The SIS has a role in the assessment of PMB. When the endometrial echo obtained by ultrasonography is unclear, the instillation of sterile saline will outline the cavity and improve diagnostic performance. A postmenopausal woman with vaginal bleeding has a pre-test probability of endometrial cancer of approximately $10 \%$. Her probability of cancer is reduced to $1 \%$ following a normal transvaginal scan [25]. It is important to emphasize that endometrial sampling should be considered mandatory in women where the endometrium cannot be measured because endometrial pathology, and even endometrial cancer, is not an uncommon finding in these women. In women managed conservatively (i.e. endometrial thickness $<4 \mathrm{~mm}$ ), re-bleeding occurs in 6 $27 \%$ of cases, and endometrial pathology is rarely found in those with an endometrial thickness of $<4 \mathrm{~mm}$ on repeat TVS [26, 27]; however, if the endometrium is $>4 \mathrm{~mm}$ on a repeat ultrasound scan, a biopsy is indicated to exclude endometrial pathology. Fluid in the endometrial cavity may be seen in postmenopausal women but is not thought to be of significance (Fig. 3) [28, 29, 30].

\section{Irregular bleeding on hormone replacement therapy}

Up to $10 \%$ of women on HRT report unscheduled vaginal bleeding. There are a variety of hormone replacement preparations available on the market. It is essential to know what type of preparation the patient is on prior to assessing the endometrium, as this may affect the endometrial appearance. For a 4-mm endometrial thickness cutoff, the number of women with false-positive results is higher among women using HRT (23\%) compared with non-users $(8 \%)$ [25]. The higher false-positive results seen in HRT users are related to the day of the cycle when the scan is performed. For patients taking sequential HRT 


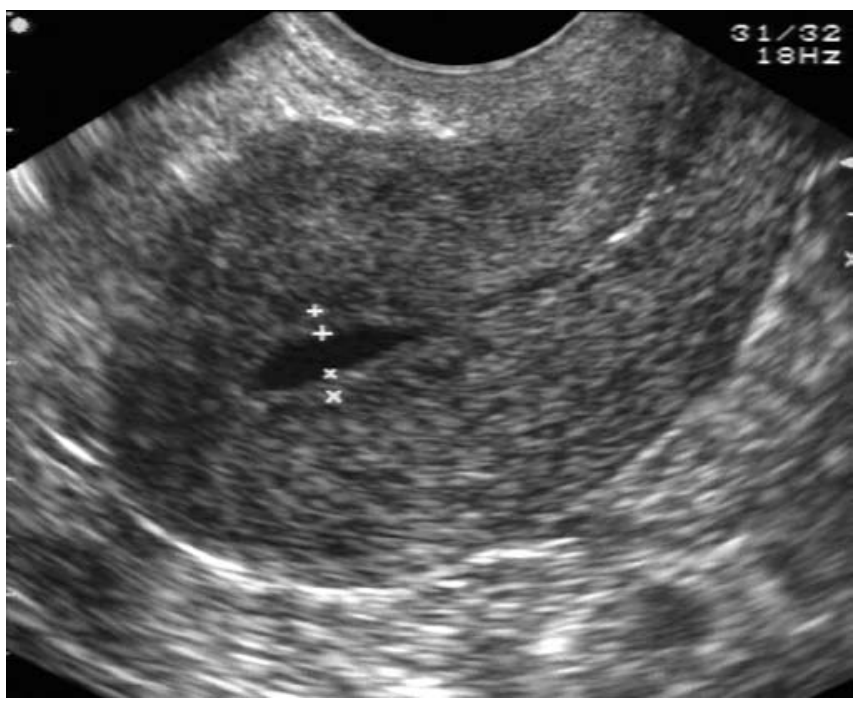

Fig. 3 Sagittal transvaginal view of an anteverted uterus with a 4-mm endometrium and free fluid in the cavity

the timing of an ultrasound scan suggested for optimal results is between 5 and 10 days from the end of the progestogen phase $[30,31]$. In contrast, TVS can be performed at any time in women receiving continuous HRT. Omodei et al. have shown that the ET does not differ between women taking sequential compared with those on continuous combined HRT (3.6 vs $3.2 \mathrm{~mm}$ ), if the measurement is taken on the fifth to tenth day following the last progestogen tablet [32]. A woman with a $1 \%$ risk of cancer, which is the risk associated with vaginal bleeding in a postmenopausal woman using combined HRT, will have a $0.1 \%$ risk of cancer following a negative $(\leq 4 \mathrm{~mm})$ ultrasound examination result.

\section{Tamoxifen and the endometrium}

Tamoxifen is used as adjuvant therapy in women diagnosed with breast cancer and more recently its effectiveness as a chemo-prevention agent has been established [33]. Tamoxifen use is associated with an increased risk of developing endometrial cancer ( 2 of 1000 tamoxifen treated women). The ultrasound appearance of the endometrium in women taking tamoxifen may be difficult to interpret. It may appear as thickened cystic endometrium, and using SIS, $50 \%$ of such cases have been shown to harbour large endometrial polyps [34]. The remaining cases have sub-endometrial cystic changes with thin atrophic endometrium. For women who have abnormal bleeding on tamoxifen the ultrasound data are unclear and it is advisable to seek histological confirmation that the cavity is normal.

The TVS has also been proposed as a non-invasive means of screening for endometrial cancer in tamoxifentreated women. Kedar et al. evaluated 111 asymptomatic at risk women randomly assigned to tamoxifen or placebo in a pilot chemo-prevention study [34]. The TVS was performed after a median time of 2 years and the mean endometrial thickness in the tamoxifen-treated group was nearly twice that of the placebo group. Although no cancers were detected in this study, 10 women had endometrial hyperplasia in the tamoxifen group. They concluded that an endometrial thickness $>8 \mathrm{~mm}$ had a $100 \%$ positive predictive value at detecting endometrial pathology. Other authors have published conflicting data questioning the efficacy of TVS as a surveillance method $[35,36,37]$. Timmerman et al. compared the ability of TVS with SIS to office hysteroscopy, in detecting endometrial pathology in women on adjuvant tamoxifen therapy [9]. In this randomised crossover study there was no difference in the sensitivity and specificity of TVS/SIS and hysteroscopy; however, two endometrial cancers were detected by ultrasound alone. The TVS/SIS was more acceptable to the patients.

Pre-treatment screening has also been suggested. Berliere et al screened 264 women with breast cancer and found that 17\% (46 of 264) of asymptomatic postmenopausal had a thickened endometrial lining prior to tamoxifen therapy [38]. Hysteroscopy confirmed submucous myoma $(n=7)$, benign polyps $(n=34)$, simple hyperplasia $(n=3)$, atypical hyperplasia $(n=1)$ and endometrial cancer $(n=1)$. Of the patients who subsequently developed pre-malignant or malignant conditions on tamoxifen therapy, $80 \%$ had had an endometrial lesion at pre-treatment assessment. This suggests that pretreatment assessment might identify women at risk of developing endometrial cancer.

The small increase in risk of endometrial cancer is outweighed by the benefits tamoxifen provides for women who have suffered from or who are at risk of breast cancer. Pre-treatment assessment prior to tamoxifen therapy appears encouraging; however, its cost-effectiveness needs to be assessed prospectively as the majority of the pre-malignant and malignant endometrial lesions present with symptoms and the treatment of early-stage endometrial cancer is quite successful. Only a large randomised trial with reduction in the mortality rate form endometrial cancer as the end point could prove that endometrial cancer monitoring in patients with breast cancer who are treated with tamoxifen is useful.

\section{Menorrhagia}

Menorrhagia is a common symptom in pre- and perimenopausal women. The role of TVS in these patients is to exclude focal or global pathology. In the absence of pathology, and with a normal endometrial biopsy the patient is diagnosed with dysfunctional uterine bleeding. The common pathologies found in women with menorrhagia are fibroids, polyps and adenomyosis. 


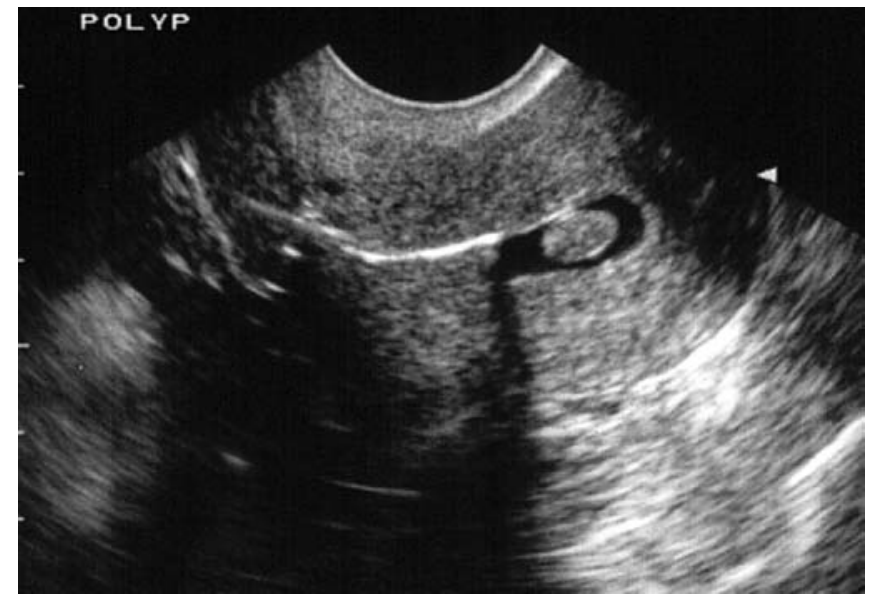

Fig. 4 Sagittal transvaginal image of a retroverted uterus. Saline infusion sonography revealed an endometrial polyp

\section{Endometrial polyps}

Recent evidence suggests that $10 \%$ of asymptomatic premenopausal women have ultrasound evidence of endometrial polyps [39], as opposed to up to $50 \%$ of premenopausal women with AUB [8, 39, 40, 41]. Endometrial polyps are sessile or pedunculated excrescences of endometrial tissue. They originate as focal hyperplasia of the basalis and develop into benign, localised overgrowth of endometrial tissue covered by epithelium [42]. On TVS they have a varied appearance; non-specific thickened endometrium, a focal echogenic area within the endometrium or occasionally as a mass in the endometrial cavity surrounded by fluid. They generally have a homogeneous texture without disruption of the myometrial-endometrial interface. Caspi et al. [43] described the bright edge of the polyp produced during TVS at the transition zone between the myometrium and the endometrial surface of the polyp. In comparison with hysteroscopy, TVS with SIS is at least as good as hysteroscopy for detecting these lesions (Fig. 4) [7, 8, 39]. Occasionally, problems may arise when distinguishing between larger polyps and submucous fibroids [8]; however, in our practice this is less common with experience. The sensitivity and specificity of TVS with SIS in the detection of endometrial polyps varies from 84 to $100 \%$ and 81 to $100 \%$, respectively $[7,8,9,44]$. Polyps are usually benign; however, the risk of malignancy developing in an endometrial polyp is $0.5 \%$ [45]; nonetheless, they are not regarded as a major risk for the development of carcinoma [46]. Although the risk of malignancy is small, polyps are often removed by hysteroscopic resection in both symptomatic and asymptomatic women. Hysteroscopic resection is not without risk, so removing them all may be too aggressive and leaving them all may be dangerous.

Timmerman et al. [47] described the use of colour Doppler as an alternative to SIS and hysteroscopy as a second stage test after TVS. Patients with a clearly visible pedicle artery reaching the central part of the endometrium were regarded as test positive. In this series the pedicle artery sign had a sensitivity of $76.4 \%$, specificity of $95.3 \%$ and a positive and negative predict value of 81.3 and $93.8 \%$, respectively. The high negative predictive value of colour Doppler may negate the need for SIS or hysteroscopy in selected patients. In another recent study [48] blood flow impedance (resistive index, pulsatility index) failed to predict histological type in a cohort of symptomatic and asymptomatic women with endometrial polyps. This study suggests that the objective assessment of blood flow impedance within an endometrial polyp or its size can replace surgical removal and pathologic evaluation to predict histological type; however, the natural history of endometrial polyps is still unclear, and the question as to whether all endometrial polyps should be removed is valid. In a recent study De Waay et al. [49], over a 2.5-year period, noted that small endometrial polyps frequently regressed, whereas larger polyps were more likely to persist and were associated with the development of abnormal bleeding. It is clear that further prospective studies are needed to assess the natural history of polyps to help develop appropriate treatment strategies. For the moment, the detection of such focal pathology is an intrinsic part of the evaluation of women with abnormal bleeding.

\section{Uterine fibroids}

Fibroids occur in up to $40 \%$ of women over the age of 35 years, and are seen more frequently in women of AfroCaribbean decent. They consist of smooth muscle and varying degrees of connective tissue. The ultrasound appearances are varied. Before menopause they tend to be a well-defined heterogeneous or hypoechoeic uterine mass in nature and cystic areas may be visualized within the fibroid if it is degenerating. Areas of calcification tend to be seen more often in postmenopausal women. Submucosal fibroids distort the uterine cavity and have an inhomogeneous texture with possible continuity with the myometrium (Fig. 5). Their accurate classification with regard to size, number and location allows selection for transcervical resection in appropriate cases. They are classified according to the European Society of Gynaecologic Endoscopy Classification: type 0 (pedunculated submucous fibroid without intramural extension); type I (sessile and with an intramural part of $<50 \%$ ); and type II (with an intramural part of $50 \%$ or more). Fedele et al. [21] demonstrated the sensitivity and specificity of TVS for the diagnosis of submucosal fibroids to be 100 and $94 \%$, respectively. Outpatient hysteroscopy performed on the same population had a sensitivity and specificity of 100 and $96 \%$, respectively. The only criticism of TVS in this study was its apparent inability to differentiate between endometrial polyps and submucosal fibroids. The scans in this study were performed in the secretory phase of the cycle; endometrial polyps tend to be hyperechoeic structures, easily masked by a thick secre- 


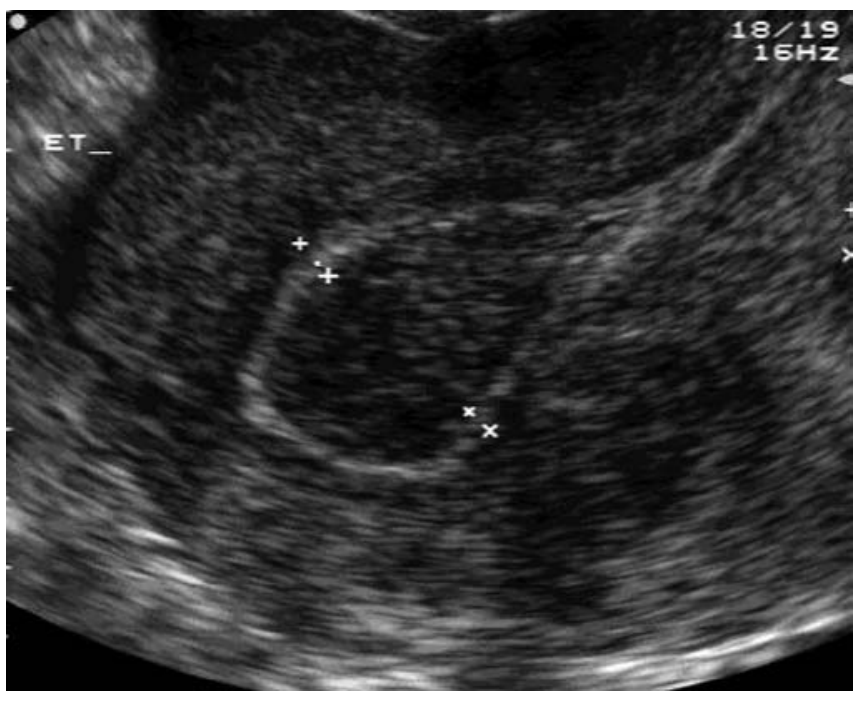

Fig. 5 Sagittal transvaginal view of an anteverted uterus. The endometrium is hyperechoeic, and there is an submucous fibroid filling the endometrial cavity. Note that the echotexture of the fibroid and the myometrium are the same

tory endometrium. By performing the scans during the proliferative phase, the distinction between intracavity fibroids and polyps is easier to make [7]. The sensitivity and specificity of TVS with SIS in the detection of submucous fibroids varies from 90 to $94 \%$ and 95 to $98 \%$, respectively $[7,8,21,44]$. In women with large fibroids extending beyond the true pelvis an abdominal ultrasound scan should be performed to ascertain their exact size and location. In our experience, menorrhagia or intermenstrual bleeding in a woman on the oral contraceptive pill should raise the suspicion of focal intracavity pathology and warrants TVS. The majority of studies have assessed the role of TVS and SIS in post- and premenopausal women together. Dueholm et al. [50] used SIS in the assessment of 470 premenopausal women with AUB. In this study TVS alone missed $24 \%$ of intracavity lesions, whereas with SIS one lesion was missed. The post-test probability of there being an abnormal cavity sfter TVS alone was $0.18(0.10-0.32)$ compared with $0.02(0.01-$ 0.11 ) with TVS and SIS. This study suggests an important role for the routine use of SIS in premenopausal women, and other prospective studies are needed to assess this role further.

\section{Adenomyosis}

Adenomyosis is a common gynaecological disorder that affects women of reproductive age. Patients are often multiparous and present with menorrhagia and secondary dysmenorrhoea. Adenomyosis is characterised by the presence of endometrial glands and stroma with smooth muscle hyperplasia, which usually affects the inner third of the myometrium, and rarely affects the cervix. Until recently, the diagnosis was rarely made prior to hyster- ectomy; however, the improved image quality obtained by TVS has led to a significant improvement in diagnostic accuracy. Adenomyosis may be nodular with circumscribed aggregates or diffuse with foci scattered throughout the myometrium. The ultrasound appearance is varied and includes hypoechoeic areas, heterogeneous myometrial echotexture, asymmetric uterine enlargement and subendometrial cysts. In the literature the sensitivity and specificity of the ultrasound diagnosis of adenomyosis is $53-89 \%$ and $75-96 \%$, respectively $[51,52,53,54,55]$. This suggests that the diagnosis is operator dependent, and that different histological criteria and sampling techniques were used in these studies.

\section{Adnexal pathology}

In women with AUB, TVS affords assessment of the adnexa. Ovarian and tubal pathology can be accurately characterised in experienced hands. Jones and Bourne [3] found adnexal pathology in $13 \%$ of patients attending an abnormal uterine bleeding one-stop clinic. The discovery of adnexal pathology may have an immediate impact on management; otherwise, any incidental findings can be surgically treated electively or followed up conservatively.

\section{Conclusion}

The AUB is frequently a cause for concern in both preand postmenopausal women. Although the majority of the pathology is benign, serious underlying pathology, such as endometrial cancer, should be excluded. Investigations should be outpatient based, with the use of ultrasonography, outpatient hysteroscopy and endometrial biopsy devices. The TVS should be the primary diagnostic tool in the one-stop clinical setting, as when combined with SIS it compares favourably with hysteroscopy. Transvaginal ultrasonography is the least invasive investigative technique available for the investigation of AUB and provides additional information about adnexal pathology. It is well tolerated by patients and provides accurate reproducible images of the pelvic viscera. Experience in the use of TVS is necessary and knowledge of the stage of the menstrual cycle in premenopausal women is essential for accurate interpretation of the findings. The SIS should be used when the endometrial cavity is not seen clearly. This outpatient TVS-based one-stop approach allows patients to be triaged, thus facilitating rapid diagnosis and immediate decisions regarding management. Postmenopausal women can be reassured that in the presence of a thin endometrium they are extremely unlikely to have any sinister endometrial pathology. In premenopausal women, having excluded focal pathology, patients can be treated for dysfunctional uterine bleeding, with medical therapy, progesterone releasing intrauterine devices, endometrial ablation or hysterectomy. Those patients with focal endometrial pathology can be selected for operative 
hysteroscopy as a day case procedure following a single visit to the hospital. Diagnostic hysteroscopy should be reserved for cases where SIS has been unsuccessful at elucidating the endometrial cavity, and in experienced hands this should be a rare occurrence. With the advances in ultrasound technology and improved training in ultrasonography, in the near future the use of a small portable transvaginal ultrasound machine by a gynaecologist in the outpatient setting will become an intrinsic part of the gynaecological examination of women with AUB.

\section{References}

1. Emanuel MH, Ankum WM, Verdel MJ, Hart AA (1996) The reproducibility of the results of transvaginal sonography of the uterus in patients with abnormal uterine bleeding. Ultrasound Obstet Gynecol 8:346-349

2. Dueholm M, Laursen H, Knudsen UB (1999) A simple one-stop menstrual problem clinic with use of hysterosonography for the diagnosis of abnormal uterine bleeding. Acta Obstet Gynecol Scand 78:150-154

3. Jones K, Bourne T (2001) The feasibility of a "one stop" ultrasound-based clinic for the diagnosis and management of abnormal uterine bleeding. Ultrasound Obstet Gynecol 17:517521

4. Bourne T, Lawton F, Leather A, Granberg S, Campbell S, Collins WP (1994) Use of intracavity saline instillation and transvaginal ultrasonography to detect a tamoxifen associated endometrial polyp. Ultrasound Obstet Gynecol 2:73-75

5. Syrop CH, Sahakian V (1992) Transvaginal sonographic detection of endometrial polyps with fluid contrast augmentation. Obstet Gynecol 79:1041-1043

6. Parsons AK, Lense JJ. Sonohysterography for endometrial abnormalities: preliminary results. J Clin Ultrasound 1993;21(2):87-95

7. Schwarzler P, Concin H, Bosch H, Berlinger A, Wohlgenannt K, Collins WP et al. (1998) An evaluation of sonohysterography and diagnostic hysteroscopy for the assessment of intrauterine pathology. Ultrasound Obstet Gynecol 11:337-342

8. Widrich T, Bradley LD, Mitchinson AR, Collins RL (1996) Comparison of saline infusion sonography with office hysteroscopy for the evaluation of the endometrium. Am J Obstet Gynecol 174:1327-1334

9. Timmerman D, Deprest J, Bourne T, Van den Berghe I, Collins WP, Vergote I (1998) A randomized trial on the use of ultrasonography or office hysteroscopy for endometrial assessment in postmenopausal patients with breast cancer who were treated with tamoxifen. Am J Obstet Gynecol 179:62-70

10. Granberg S, Wikland M, Karlsson B, Norstrom A, Friberg LG (1991) Endometrial thickness as measured by endovaginal ultrasonography for identifying endometrial abnormality. Am J Obstet Gynecol 164:47-52

11. Granberg S, Bourne T (1995) Transvaginal ultrasound of endometrial disorders in postmenopausal women. Ultrasound Quarterly 13:61-74

12. Karlsson B, Granberg S, Wikland M, Ylostalo P, Torvid K, Marsal K et al. (1995) Transvaginal ultrasonography of the endometrium in women with postmenopausal bleeding: a Nordic multicenter study. Am J Obstet Gynecol 172:1488-1494

13. Ferrazzi E, Torri V, Trio D, Zannoni E, Filiberto S, Dordoni D (1996) Sonographic endometrial thickness: a useful test to predict atrophy in patients with postmenopausal bleeding. An Italian multicenter study. Ultrasound Obstet Gynecol 7:315321

14. Bourne T, Hamberger L, Hahlin M, Granberg S (1997) Ultrasound in gynecology: endometrium. Int J Gynaecol Obstet 56:115-127
15. Santolaya-Forgas J (1992) Physiology of the menstrual cycle by ultrasonography. J Ultrasound Med 11:139-142

16. Fleischer AC, Herbert CM, Sacks GA, Wentz AC, Entman SS, James AE Jr (1986) Sonography of the endometrium during conception and nonconception cycles of in vitro fertilization and embryo transfer. Fertil Steril 46:442-447

17. Roman JD, Trivedi AN (1999) Implementation of an outpatient hysteroscopy clinic at Waikato Women's Hospital report of the first 60 cases. N Z Med J 112:253-255

18. Baskett TF, O'Connor H, Magos AL (1996) A comprehensive one-stop menstrual problem clinic for the diagnosis and management of abnormal uterine bleeding. Br J Obstet Gynaecol 103:76-77

19. Gimpelson RJ, Rappold HO (1988) A comparative study between panoramic hysteroscopy with directed biopsies and dilatation and curettage. A review of 276 cases. Am J Obstet Gynecol 158:489-492

20. Mencaglia L, Perino A, Hamou J (1987) Hysteroscopy in perimenopausal and postmenopausal women with abnormal uterine bleeding. J Reprod Med 32:577-582

21. Fedele L, Bianchi S, Dorta M, Brioschi D, Zanotti F, Vercellini P (1991) Transvaginal ultrasonography versus hysteroscopy in the diagnosis of uterine submucous myomas. Obstet Gynecol 77:745-748

22. Krampl E, Bourne T, Hurlen-Solbakken H, Istre O (2001) Transvaginal ultrasonography sonohysterography and operative hysteroscopy for the evaluation of abnormal uterine bleeding. Acta Obstet Gynecol Scand 80:616-622

23. Goldstein SR, Nachtigall M, Snyder JR, Nachtigall L (1990) Endometrial assessment by vaginal ultrasonography before endometrial sampling in patients with postmenopausal bleeding. Am J Obstet Gynecol 163:119-123

24. Varner RE, Sparks JM, Cameron CD, Roberts LL, Soong SJ (1991) Transvaginal sonography of the endometrium in postmenopausal women. Obstet Gynecol 78:195-199

25. Smith-Bindman R, Kerlikowske K, Feldstein VA, Subak L, Scheidler J, Segal M et al. (1998) Endovaginal ultrasound to exclude endometrial cancer and other endometrial abnormalities. J Am Med Assoc 280:1510-1517

26. Gull B, Carlsson S, Karlsson B, Ylostalo P, Milsom I, Granberg S (2000) Transvaginal ultrasonography of the endometrium in women with postmenopausal bleeding: Is it always necessary to perform an endometrial biopsy? Am J Obstet Gynecol 182:509-515

27. Epstein E, Valentin L (2001) Rebleeding and endometrial growth in women with postmenopausal bleeding and endometrial thickness $<5 \mathrm{~mm}$ managed by dilataion and curettage or ultrasound follow-up: a ramdomised contolled study. Ultrasound Obstet Gynecol 18:499-504

28. Gull B, Karlsson B, Wikland M, Milsom I, Granberg S (1998) Factors influencing the presence of uterine cavity fluid in a random sample of asymptomatic postmenopausal women. Acta Obstet Gynecol Scand 77:751-757

29. Goldstein SR (1994) Postmenopausal endometrial fluid collections revisited: look at the doughnut rather than the hole. Obstet Gynecol 83:738-740

30. Levine D, Gosink BB, Johnson LA (1995) Change in endometrial thickness in postmenopausal women undergoing hormone replacement therapy. Radiology 197:603-608

31. Doren M, Suselbeck B, Schneider HP, Holzgreve W (1997) Uterine perfusion and endometrial thickness in postmenopausal women on long-term continuous combined estrogen and progestogen replacement. Ultrasound Obstet Gynecol 9:113119

32. Omodei U, Ferrazzia E, Ruggeri C, Palai N, Fallo L, Dordoni D et al. (2000) Endometrial thickness and histological abnormalities in women on hormonal replacement therapy: a transvaginal ultrasound/hysteroscopic study. Ultrasound Obstet Gynecol $15: 317-320$

33. Fisher B, Costantino JP, Wickerham DL, Redmond CK, Kavanah M, Cronin WM et al. (1998) Tamoxifen for prevention of breast cancer: report of the National Surgical Adjuvant 
Breast and Bowel Project P-1 Study. J Natl Cancer Inst 90:1371-1388

34. Kedar RP, Bourne TH, Powles TJ, Collins WP, Ashley SE, Cosgrove DO et al. (1994) Effects of tamoxifen on uterus and ovaries of postmenopausal women in a randomised breast cancer prevention trial. Lancet 343:1318-1321

35. Bertelli G, Venturini M, Del Mastro L, Garrone O, Cosso M, Gustavino C et al. (1998) Tamoxifen and the endometrium: findings of pelvic ultrasound examination and endometrial biopsy in asymptomatic breast cancer patients. Breast Cancer Res Treat 47:41-46

36. Cecchini S, Ciatto S, Bonardi R, Mazzotta A, Grazzini G, Pacini P et al. (1996) Screening by ultrasonography for endometrial carcinoma in postmenopausal breast cancer patients under adjuvant tamoxifen. Gynecol Oncol 60:409-411

37. Mourits MJ, Van der Zee AG, Willemse PH, Ten Hoor KA, Hollema H, De Vries EG (1999) Discrepancy between ultrasonography and hysteroscopy and histology of endometrium in postmenopausal breast cancer patients using tamoxifen. Gynecol Oncol 73:21-26

38. Berliere M, Galant C, Gillerot S, Charles A, Donnez J (1998) Endometrial evaluation prior to tamoxifen: preliminary results of a prospective study. Bull Cancer 85:721-724 [in French]

39. Clevenger-Hoeft M, Syrop CH, Stovall DW, Van Voorhis BJ (1999) Sonohysterography in premenopausal women with and without abnormal bleeding. Obstet Gynecol 94:516-520

40. de Vries LD, Dijkhuizen FP, Mol BW, Brolmann HA, Moret E, Heintz AP (2000) Comparison of transvaginal sonography, saline infusion sonography, and hysteroscopy in premenopausal women with abnormal uterine bleeding. J Clin Ultrasound 28:217-223

41. Goldstein SR (1994) Use of ultrasonohysterography for triage of perimenopausal patients with unexplained uterine bleeding. Am J Obstet Gynecol 170:565-570

42. Dallenbach C, Hellweg N (1985) Endometrium. In: histopathology of the endometrium. Springer, Berlin Heidelberg New York

43. Caspi B, Appelman Z, Goldchmit R, Ashkenazi M, Haruvy Y, Hagay Z (2000) The bright edge of the endometrial polyp. Ultrasound Obstet Gynecol 15:327-330

44. Bernard JP, Rizk E, Camatte S, Robin F, Taurelle R, Lecuru F (2001) Saline contrast sonohysterography in the preoperative assessment of benign intrauterine disorders. Ultrasound Obstet Gynecol 17:145-149

45. Wolfe SA, Mackles A (1962) Malignant lesions arising from benign endometrial polyps. Obstet Gynecol 20:542-551

46. Peterson WF, Novak ER (1956) Endometrial polyps. Obstet Gynecol 8:40-49

47. Timmerman D, Verguts J, Konstantinovic ML, Moerman P, Van Schoubroeck D, Deprest J et al. (2003) The pedicle artery sign based on sonography with color Doppler imaging can replace second-stage tests in women with abnormal vaginal bleeding. Ultrasound Obstet Gynecol 22:166-171

48. Goldstein SR, Monteagudo A, Popiolek D, Mayberry P, TimorTritsch I (2002) Evaluation of endometrial polyps. Am J Obstet Gynecol 186:669-674

49. DeWaay DJ, Syrop CH, Nygaard IE, Davis WA, Van Voorhis BJ (2002) Natural history of uterine polyps and leiomyomata. Obstet Gynecol 100:3-7

50. Dueholm M, Forman A, Jensen ML, Laursen H, Kracht P (2001) Transvaginal sonography combined with saline contrast sonohysterography in evaluating the uterine cavity in premenopausal patients with abnormal uterine bleeding. Ultrasound Obstet Gynecol 18:54-61

51. Reinhold C, McCarthy S, Bret PM, Mehio A, Atri M, Zakarian $\mathrm{R}$ et al. (1996) Diffuse adenomyosis: comparison of endovaginal US and MR imaging with histopathologic correlation. Radiology 199:151-158

52. Reinhold C, Atri M, Mehio A, Zakarian R, Aldis AE, Bret PM (1995) Diffuse uterine adenomyosis: morphologic criteria and diagnostic accuracy of endovaginal sonography. Radiology 197:609-614

53. Fedele L, Bianchi S, Dorta M, Arcaini L, Zanotti F, Carinelli S (1992) Transvaginal ultrasonography in the diagnosis of diffuse adenomyosis. Fertil Steril 58:94-97

54. Atzori E, Tronci C, Sionis L (1996) Transvaginal ultrasound in the diagnosis of diffuse adenomyosis. Gynecol Obstet Invest 42:39-41

55. Brosens JJ, de Souza NM, Barker FG, Paraschos T, Winston RM (1995) Endovaginal ultrasonography in the diagnosis of adenomyosis uteri: identifying the predictive characteristics. $\mathrm{Br}$ J Obstet Gynaecol 102:471-474 